Table 1. Characteristics of patients according to gender

\begin{tabular}{|c|c|c|c|c|c|}
\hline Findings & $\begin{array}{l}\text { Patients, } \mathbf{n} \\
(\%)\end{array}$ & $\begin{array}{c}\text { Male } \\
(n=282)\end{array}$ & $\begin{array}{l}\text { Female } \\
(n=383)\end{array}$ & OR $(95 \% \mathrm{Cl})$ & $p$ \\
\hline GU, n (\%) & $571,(85.9)$ & $\begin{array}{c}230 \\
(81.6)\end{array}$ & $341(89)$ & $\begin{array}{l}1.84(1.18- \\
2.85)\end{array}$ & 0.006 \\
\hline EN, n (\%) & $376,(56.5)$ & $\begin{array}{c}151 \\
(53.5)\end{array}$ & $\begin{array}{c}225 \\
(58.7)\end{array}$ & $\begin{array}{c}1.24(0.91- \\
1.69)\end{array}$ & 0.181 \\
\hline PPL, n (\%) & $438,(65.9)$ & $\begin{array}{c}215 \\
(76.5)\end{array}$ & $\begin{array}{c}223 \\
(58.2)\end{array}$ & $\begin{array}{l}0.43(0.30- \\
0.60)\end{array}$ & $<0.001$ \\
\hline Ocular, n (\%) & $217,(32.6)$ & $\begin{array}{c}109 \\
(38.7)\end{array}$ & $\begin{array}{c}108 \\
(28.2)\end{array}$ & $\begin{array}{c}0.62(0.45- \\
086)\end{array}$ & 0.004 \\
\hline Joint involvement, $\mathrm{n}(\%)$ & $328,(49.3)$ & $\begin{array}{c}114 \\
(40.4)\end{array}$ & $\begin{array}{c}214 \\
(55.9)\end{array}$ & $\begin{array}{l}1.87(1.37- \\
2.55)\end{array}$ & $<0.001$ \\
\hline Vascular involvement, $\mathrm{n}(\%)$ & $144,(21.7)$ & $\begin{array}{c}99 \\
(35.1)\end{array}$ & $\begin{array}{c}45 \\
(11.7)\end{array}$ & $\begin{array}{l}0.25(0.17- \\
0.37)\end{array}$ & $<0.001$ \\
\hline GI involvement, $\mathrm{n}(\%)$ & $18,(2.7)$ & $8(2.8)$ & $10(2.6)$ & $\begin{array}{l}0.92(0.36- \\
2.36)\end{array}$ & 0.859 \\
\hline Headache, $(n=581), n(\%)$ & $200(34.4)$ & $46(19)$ & $\begin{array}{c}154 \\
(45.4)\end{array}$ & $\begin{array}{l}3.55(2.41- \\
5.22)\end{array}$ & $<0.001$ \\
\hline $\begin{array}{l}\text { Neurobehçet's disease, n } \\
\text { (\%) }\end{array}$ & $32,(4.8)$ & $13(4.6)$ & $19(5.0)$ & $\begin{array}{l}1.07(0.52- \\
2.21)\end{array}$ & 0.850 \\
\hline $\begin{array}{l}\text { Pathergy positivity ( } \mathrm{n}= \\
384), \mathrm{n}(\%)\end{array}$ & $233(60.7)$ & $\begin{array}{c}91 \\
(54.5)\end{array}$ & $\begin{array}{c}142 \\
(65.4)\end{array}$ & $\begin{array}{c}1.58(1.05- \\
2.39)\end{array}$ & 0.029 \\
\hline
\end{tabular}

Table 2. Comparison of the age according to the presence of clinical findings

\begin{tabular}{lccc}
\hline Findings & $\mathbf{n}$ & $\begin{array}{c}\text { Median age, years } \\
(\text { IQR })\end{array}$ & $\mathbf{p}$ \\
\hline GU & $(+)=571$ & $30.4(11.7)$ & $\mathbf{0 . 0 0 6}$ \\
& $(-)=94$ & $34.1(12.5)$ & \\
EN & $(+)=376$ & $30.3(11.4)$ & $\mathbf{0 . 0 2 5}$ \\
PPL & $(-)=289$ & $31.5(13.3)$ & \\
& $(+)=438$ & $30.5(12.0)$ & 0.569 \\
Ocular & $(-)=227$ & $30.5(11.1)$ & \\
& $(+)=217$ & $30.5(12.0)$ & 0.699 \\
Joint involvement & $(-)=448$ & $30.5(11.5)$ & 0.723 \\
& $(+)=328$ & $30.5(12.5)$ & \\
Vascular involvement & $(-)=337$ & $31.1(11.4)$ & 0.007 \\
& $(+)=144$ & $29.6(10.8)$ & 0.211 \\
Gl involvement & $(-)=521$ & $31.2(12.0)$ & \\
& $(+)=18$ & $27.8(10.9)$ & 0.374 \\
Headache, (n=581) & $(-)=647$ & $30.5(11.8)$ & \\
& $(+)=200$ & $30.4(12.9)$ & 0.160 \\
Neurobehçet's & $(-)=381$ & $31.0(11.6)$ & \\
disease & $(+)=32$ & $29.5(7.7)$ & 0.446 \\
Pathergy (n=384) & $(-)=633$ & $30.5(11.8)$ & \\
& Pozitive:233 & $30.8(12.6)$ & \\
\hline
\end{tabular}

Disclosure of Interests: None declared

DOI: 10.1136/annrheumdis-2019-eular.4612

\section{FRI0296 INPATIENT PREVALENCE, MORTALITY, EXPENDITURES AND COMORBIDITIES OF POLYARTERITIS NODOSA: NATIONWIDE INPATIENT SAMPLE 2014}

Patompong Ungprasert ${ }^{1}$, Karn Wijarnpreecha. ${ }^{2}$, Wisit Cheungpasitporn ${ }^{3}$, Charat Thongprayoon ${ }^{4}$, Paul Kroner ${ }^{2} .{ }^{1}$ Faculty of Medicine Siriraj Hospital, Mahidol University, Clinical epidemiology unit, Bangkok, Thailand; ${ }^{2}$ Mayo Clinic Florida, Jacksonville, United States of America; ${ }^{3}$ University of Mississippi Medical Center, Jackson, United States of America; ${ }^{4}$ Mayo Clinic Rochester, Rochester, United States of America

Background: Polyarteritis nodosa (PAN) is a systemic necrotizing vasculitis that characteristically affects medium-sized arteries of the intestine, kidneys and soft tissue [1]. Little is known about the inpatient burden, expenditures and association with comorbidities of PAN.

Objectives: To investigate the inpatient prevalence, expenditures and comorbidities of patients with PAN using a national inpatient database. Methods: Patients with PAN were identified from the Nationwide Inpatient Sample (NIS) database of the years 2014 using ICD-9 diagnostic code. NIS is a publicly available inpatient database that contained data of over 7 million hospital stays, which are a $20 \%$ stratified sample of over 4,000 non-federal acute care hospitals across all the regions of the United States (US). Data on patient characteristics, comorbidities, resource utilization and expenditures was collected. The primary outcome was determining the inpatient prevalence of PAN in hospitalized patients in the US. Secondary outcomes included determining inpatient mortality, inpatient morbidity (measured by shock, ICU admission and multi-organ failure), comorbidities, hospital length of stay (LOS) and total hospital costs and charges. The most common reasons for hospitalization were abstracted utilizing the top principal diagnoses in patients with PAN. A cohort of patients without PAN was also identified from the same database to serve as comparators for analysis of comorbidities. Multivariate regression analysis was used to adjust for age, gender, ethnicity, Charlson Comorbidity Index, income, hospital region, location, size and teaching status.

Results: A total of 5,255 patients with PAN were included in the study The mean age was 58.8 years, and $57 \%$ were female. The top reasons for hospitalization were PAN itself $(15.3 \%)$, sepsis $(6.9 \%)$, acute kidney injury $(4.8 \%)$ and acute respiratory failure $(2.5 \%)$. For the primary outcome, the inpatient prevalence of PAN was found to be 14.9 cases per 100,000 admissions. For secondary outcomes, patients with PAN displayed increased adjusted odds of mortality (OR:1.60, $\mathrm{p}<0.01)$, shock (OR:1.81, $p<0.01$ ), ICU admission (OR:2.06, $p<0.01$ ) and multiorgan failure (OR:3.45, p<0.01) compared to patients without PAN. Patients with PAN also displayed significantly higher hospital costs (additional adjusted mean [aAM]: $\$ 10,780, \quad \mathrm{p}<0.01$ ), hospitalization charges (aAM: $\$ 39,915, \quad \mathrm{p}<0.01$ ) and LOS (aAM: 4.2 days, $\mathrm{p}<0.01$ ) compared to patients without PAN Patients with PAN displayed a significant association with several comor bidities (Table 1).

Conclusion: The inpatient prevalence of PAN was higher than what would be expected from the overall prevalence. The mean total hospital costs and total hospitalization charges for patients with PAN were higher than patients without PAN. Analysis of comorbidities found significantly higher odds of several comorbidities even after adjusting for potential confounders.

\section{REFERENCE:}

[1] Forbess L, Bannykh S. Polyarteritis nodosa. Rheum Dis Clin N Am 2015;41:33-46

Table 1. Adjusted ORs comparing the prevalence of comorbidities between patients with PAN versus patients without PAN

\begin{tabular}{lccc}
\hline & Adjusted odds ratio & $\mathbf{9 5 \%} \mathbf{C l}$ & $\boldsymbol{p}$-value \\
\hline DVT & 2.07 & $1.60-2.66$ & $<0.01$ \\
PE & 2.12 & $1.62-2.78$ & $<0.01$ \\
AMI & 1.27 & $0.79-2.04$ & 0.32 \\
CHF & 1.10 & $0.92-1.32$ & 0.32 \\
Arrythmia & 1.05 & $0.86-1.29$ & 0.61 \\
Peripheral vascular disease & 0.86 & $0.61-1.19$ & 0.36 \\
Acute kidney injury & 4.14 & $3.54-4.85$ & $<0.01$ \\
Chronic kidney disease & 9.70 & $7.69-12.22$ & $<0.01$ \\
ESRD & 5.51 & $4.41-6.88$ & $<0.01$ \\
Intestinal perforation & 3.78 & $1.59-9.01$ & $<0.01$ \\
HBV infection & 5.01 & $2.80-8.95$ & $<0.01$ \\
HCV infection & 1.65 & $1.12-2.42$ & 0.01 \\
Sepsis & 1.87 & $1.54-2.28$ & $<0.01$ \\
\hline
\end{tabular}

Disclosure of Interests: None declared

DOI: 10.1136/annrheumdis-2019-eular.6577

\section{FRI0297 CLINICAL FEATURES, TREATMENT MODALITIES AND RELAPSE RATES IN GREEK PATIENTS WITH RETROPERITONEAL FIBROSIS}

Aliki Venetsanopoulou ${ }^{1}$, Evangelia Zampeli ${ }^{2}$, Sophia Christaki ${ }^{3}$,

Ourania Argyropoulou ${ }^{1}$, Kyriaki A. Boki ${ }^{4}$, Menelaos N. Manoussakis ${ }^{1}$, Foteini N. Skopouli ${ }^{3}$, Athanasios Tzioufas ${ }^{1}$, Haralampos M. Moutsopoulos ${ }^{5} .{ }^{1}$ School of Medicine, National and Kapodistrian University of Athens, Pathophysiology, Athens, Greece, ${ }^{2}$ Athens Medical School, Sotiria General Hospital, 3rd Internal Medicine Department, Athens, Greece; ${ }^{3}$ Euroclinic Hospital, Department of Internal Medicine and Clinical Immunology, Athens, Greece; ${ }^{4}$ Sismanoglion Hospital, 3Rheumatology Unit, Athens, Greece; ${ }^{5}$ Academy of Athens, Athens, Greece

Background: Retroperitoneal fibrosis (RPF) is a rare disease of unknown etiology characterized by deposition of fibro-inflammatory tissue around the infra-renal abdominal aorta. The process may involve adjacent structures leading to complications, the most frequent being ureteral obstruction [1]. RPF is mainly idiopathic (iRPF), yet it might be secondary to malignancies, infections, drugs, or radiotherapy [2]. Recent data argue that iRPF could be part of the $\operatorname{lgG}_{4}$-related diseases [3]. Diagnosis is aided by imaging studies (abdomen CT/MRI), but in patients with newly diagnosed RPF, excluding malignancy is mandatory [2].

Objectives: The aim of our study was a) to describe the presenting clinical, laboratory, imaging features and treatment modalities used in patients 
with iRPF from four tertiary medical units in Greece and b) to evaluate factors potentially associated with disease relapse.

Methods: Medical records of patients diagnosed with RPF from 20002018 in four rheumatology units (Laiko, Euroclinic, Sismanoglion and Sotiria Hospitals) were retrospectively evaluated. Sixty-seven patients with iRPF were included in the study.

Results: The median age at diagnosis was 56 years (IQR:52.0-60.0), with median disease duration 8.0 years (IQR:3.0-11.0), 58\% were smokers and $73 \%$ males. Patients more often presented with constitutional symptoms $(57 \%)$, low back pain $(63 \%)$, raised inflammatory markers $(78 \%)$, anemia $(43 \%)$ and compromised renal function (15\%). Commonest imaging findings were periaortic-periiliac mass $(46 \%)$, periaortic mass (33\%), periaortitis (25\%) and hydronephrosis (36\%) with envelopment of one $(31 \%)$ or both ureters $(18 \%)$. Tissue biopsy was requested in all patients, but was performed in only 10, with 3 having marked numbers of IgG4-positive plasma cells. Serum IgG4 was measured in 36/67 and $36 \%$ had elevated levels at diagnosis (median $224 \mathrm{mg} / \mathrm{dL}$, IQR:174-328). Clinical/laboratory/radiological presentation did not differ between patients with elevated and normal serum $\operatorname{lgG}_{4}$ levels. Steroids were first-line treatment in $93 \%$ of patients. Other immunosuppressives used as steroid-sparing agents were azathioprine (70\%), cyclophosphamide (19\%), mycophenolate-mofetil (18\%), D-penicillamine (12\%) and methotrexate $(8 \%)$. Relapse occurred in $19 \%$ of patients at a median of 36 months (IQR:18-66) after diagnosis with $69 \%$ of them being under therapy. Relapse did not correlate to initial imaging findings or to any treatment modality, yet patients with increased serum IgG4 tended to have higher relapse rate $(26 \%$ vs $11 \%, \mathrm{p}=0.071)$.

Conclusion: Diagnosis of iRPF was mostly based on imaging studies in our cohort. Steroids were used as first-line treatment. Relapse occurred in one-fifth of patients independently of initial clinical/radiographic presentation or treatment modality used. RPF patients with initially elevated serum $\operatorname{lgG}_{4}$ levels tended to have a higher relapse rate.

\section{REFERENCES:}

[1] Vaglio A, Salvarani C, Buzio C. Retroperitoneal fibrosis. Lancet 2006; 367:241-51.

[2] Brandt AS, Kamper L, Kukuk S, Haage P, Roth S. Associated findings and complications of retroperitoneal fibrosis in 204 patients: results of a urological registry. J Urol. 2011; 185:526-31.

[3] Khosroshahi A, Carruthers MN, Stone JH, Shinagare S, Sainani N, Hasserjian RP, Deshpande V. Rethinking Ormond's disease: "idiopathic" retroperitoneal fibrosis in the era of IgG4-related disease. Medicine (Baltimore). 2013; 92:82-91.

Disclosure of Interests: Aliki Venetsanopoulou: None declared, Evangelia Zampeli Speakers bureau: Roshe, Astrazeneca, Sophia Christaki: None declared, Ourania Argyropoulou: None declared, Kyriaki A. Boki: None declared, Menelaos N. Manoussakis: None declared, Foteini N. Skopouli: None declared, Athanasios Tzioufas Grant/research support from: ABBVIE, PFIZER, AMGEN, NOVARTIS, GSK, Haralampos M. Moutsopoulos: None declared

DOI: 10.1136/annrheumdis-2019-eular.4231

\section{\begin{tabular}{|l|l}
\hline FRI0298 ABNORMALITY OF PERCENTAGES AND ABSOLUTE \\
\hline
\end{tabular} NUMBERS OF CD4+T SUBSETS IN PATIENTS WITH ANCA-ASSOCIATED VASCULITIS AND ITS CORRELATIONS WITH CLINICAL INDICATORS}

Yanlin Wang, Xiang-Cong Zhao, Jing Luo. The Second Hospital of Shanxi Medical University, Taiyuan, China

Background: ANCA-associated vasculitis (AAV) is a heterogenous autoimmune disease with unknown etiology [1-2]. During the last decade, a panel of $C^{+} T$ subsets have been identified. However, the exact role and quantitative status of these subsets in AAV patients remains unclear. Objectives: We therefore investigated these $T$ cell subsets in AAV patients.

Methods: AAV patients $(n=54)$ and healthy controls $(\mathrm{HCs})(\mathrm{n}=19)$ were enrolled. Of them, ten patients initially presenting with active disease were assessed again after remission was achieved. In addition, 38 patients were renal vasculitis. Proportions and absolute numbers of peripheral $C D 4+T$ cell subsets and expression of multiplex cytokines were determined by flow cytometry (FCM). Correlations of clinical indicators with the CD4+ T cell subsets were systematically analyzed.

Results: Percentages of naive $T$ cells $(T N) \quad(p<0.001)$, terminally differentiated effector (TEMRA) T cells $(p=0.027)$ and activated Treg cells (aTreg) in AAV patients were decreased, but those of effector memory T-cell subpopulation (TEM) $(p<0.001)$, regulatory $T$ cell $($ Treg) cells and FoxP3lowCD45RA- $T$ cells were increased. Similar results were observed when we compared absolute numbers of the above corresponding cells in AAV patients and HCs, except TEM. Furthermore, the percentage of aTreg $(p=0.043)$ was decreased while that of Th17 cells $(p=0.027)$ was increased in renal vasculitis patients. A significant correlation was observed between the ratio of Th17 to Treg subset and creatinine or BUN, as well as the ratio of Th17/aTreg was significantly increased in active and renal vasculitis patient. In addition, we found that cytokine IL2 and IL-4 exhibited a downward while IL-6, IL-10, TNF, IFN- $\gamma$ and IL$17 \mathrm{~A}$ trend upward in AAV patients.

Conclusion: There were abnormally quantitative changes in CD4+ $T$ sub sets and cytokines in AVV patients, especially the decrease in the relative and absolute number of aTreg (activated Tregs), which indicates an imbalance of pro- and anti-inflammatory $T$ cells. These $T$ subsets might be associated with the ANCA-related autoimmune response and can be used as diagnosis markers for disease activity and as targets for potentially powerful therapy of AAV.

\section{REFERENCES:}

[1] Hutton H L, Holdsworth S R, Kitching A R. ANCA-Associated Vasculitis: Pathogenesis, Models, and Preclinical Testing [J]. Seminars in Nephrology, 2017, 37(5):418

[2] Kerstein A, Silke Schüler, Otávio CabralMarques, et al. Environmental factor and inflammation-driven alteration of the total peripheral T-cell compartment in granulomatosis with polyangiitis [J]. Journal of Autoimmunity, 2016, 78:79.

Disclosure of Interests: None declared

DOI: 10.1136/annrheumdis-2019-eular.4667

\section{FRI0299 THE PREVALENCE OF NON-VASCULAR PULMONARY MANIFESTATIONS IN PATIENTS WITH TAKAYASU' ARTERITIS: A RETROSPECTIVE MULTI-CENTERED COHORT STUDY}

Ayten Yazici ${ }^{1}$, Ayse Cefle ${ }^{1}$, Sema Kaymaz Tahra ${ }^{2}$, Nilüfer Alpay Kanitez ${ }^{3}$, Mete Kara ${ }^{4}$, Önay Gerçik ${ }^{5}$, Handan Yarkan Tugsal ${ }^{6}$, Fatos Onen ${ }^{6}$, Servet Akar ${ }^{5}$, Kenan Aksu' ${ }^{4}$, Gökhan Keser ${ }^{4}$, Fatma Alibaz-Oner ${ }^{2}$, Haner Direskeneli ${ }^{2} .{ }^{1}$ Kocaeli University School of Medicine, Rheumatology, Kocaeli, Turkey, ${ }^{2}$ Marmara University School of Medicine, Rheumatology, Istanbul, Turkey, ${ }^{3}$ Koc University School of Medicine, Rheumatology, Istanbul, Turkey; ${ }^{4}$ Ege University School of Medicine, Rheumatology, Izmir, Turkey; ${ }^{5}$ Katip Celebi University School of Medicine, Rheumatology, Izmir, Turkey; ${ }^{6}$ Dokuz Eylul University School of Medicine, Rheumatology, Izmir, Turkey

Background: Takayasu' arteritis (TAK) is a rare vasculitis characterized by inflammation and obliteration of intermediate to large-size arteries Even though more than $50 \%$ of patients with TAK have pulmonary artery involvement, non-vascular involvement and symptoms are uncommon.

Objectives: We aimed to investigate the frequency of non-vascular pulmonary involvement in TAK.

Methods: We assembled a retrospective cohort of patients with TAK from six different centers in Turkey. The demographics, clinical characteristics, treatment and outcomes of patients were abstracted from medical records and the computed tomography findings were evaluated for pulmonary manifestations.

Results: As of January 2019, 197 TAK patients were recruited (mean age: $42.7 \pm 13.9$ years [min-max: $17-75]$ ) to the cohort, and $88.3 \%$ of them were female. Twenty-four patients had cough and/or dyspnea and four had hemoptysis as pulmonary symptoms. In CT assessment, parenchymal infiltrations were present in four (2\%), pleural effusion in five $(2.5 \%)$, nodule/cavity in one $(0.5 \%)$, and pulmonary hemorrhage in one patient $(0.5 \%)$. The patient who had pulmonary hemorrhage had also pleural effusion at the same time. In the whole cohort, $11.2 \%$ of patients $(n=22)$ had pulmonary hypertension $(P A H)$, three of them had cough and/ or dyspnea and four of them had hemoptysis as a pulmonary symptom. Among patients with $\mathrm{PAH}$, any pulmonary involvement in CT was more frequent compared to the rest of the patients $(22.7 \%$ vs $5.1 \%, p<0.0001)$ (Table 1).

Conclusion: In this first assessment of Turkish TAK cohort, we observed non-vascular pulmonary involvement in about $5 \%$ of our patients and half of them were pleural effusions. The second most common manifestation was parenchymal infiltration with a frequency of $2 \%$. Although rare, nonvascular pulmonary manifestations should also be investigated in TAK patients, especially in patients with pulmonary hypertension. 